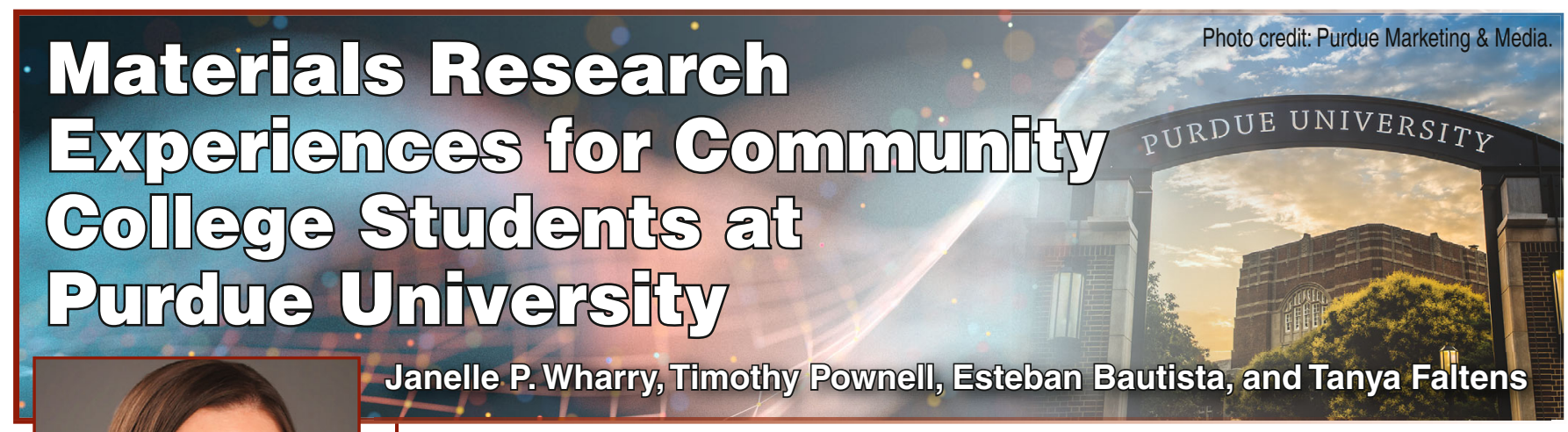

\section{Closing the Research Gap}

In the United States, more than 575,000

students are enrolled in engineering, engineering technology, computer science, mathematics, or natural science degree programs at public two-year colleges. ${ }^{1}$ Upon matriculation, nearly $80 \%$ express an intention of transferring to a four-year institution, but ultimately, only $30 \%$ make the transfer. ${ }^{1}$ Potential explanations for this gulf in transfer persistence are not well understood. However, two-year college or community college students have long been overlooked and underserved in discussions around science, technology, engineering, and math (STEM) research and engagement. As an initial step toward encouraging transfer persistence, Purdue University has stood up a summer research experience for community college students.

The concept of this research experience was motivated by the well-documented success of hands-on learning experiences and laboratories in enhancing community college student engagement. ${ }^{2-7}$ This concept also extends the success of undergraduate-level research experiences to the community college level, as a means to encourage students to pursue postbaccalaureate studies in STEM fields. ${ }^{8-14}$

\section{Success Stories at Purdue}

The community college research experience pilot program was established in 2017 through the Network for Computational Nanotechnology (NCN) - a National Science Foundation (NSF) funded multi-institutional center led by Purdue University focused on developing modeling and simulation tools to predict multiscale behaviors of nanosystems. The pilot program integrated two-year college students in the existing formalized NCN Undergraduate Research Experience
(URE), which had previously been open only to students from four-year colleges and universities.

The NCN URE is a paid summer research program focusing on applying computational simulations and developing computational tools for physical processes, systems, and devices. The most unique feature of the NCN URE program is that the student-developed computational tools are published on nanoHUB.org, a cloud-based resource for interactive simulation tools that enable research and teaching across nanotechnology. The URE participants receive training on Jupyter Notebooks and Python, providing them with the necessary skills to build a nanoHUB tool. All URE students are paired with a faculty advisor and a graduate student mentor who define their research projects and provide dayto-day guidance. Students also participate in professional development workshops, attend research seminars, and engage in networking and social activities. At the conclusion of the program, students deliver poster presentations at the NCN URE research symposium.

Through the pilot program, five students from Pasadena City College (PCC) spent eight weeks conducting guided research at Purdue. During the pilot program, the PCC students explored scientific problems spanning a broad range of materials science topics. For example, one student developed the DualfoilUQ nanoHUB tool to improve uncertainty quantification for battery electrode material performance. Two students validated the mechanical properties of powder compacts for the Powder Compaction nanoHUB tool. Another student optimized plasma treatment process parameters on liquid crystal fiber wetting.

Esteban Bautista, a first-generation college graduate, participated in the pilot 
program. During his NCN URE, Bautista investigated the long-term thermal aging of Inconel 625 and 690, comparing the performance of alloys fabricated by conventional forging to those fabricated by powder metallurgy with hot isostatic pressing (PM-HIP). By coupling his own experiments with data gathered from the archival literature, Bautista built a datascience tool on nanoHUB to predict the mechanical degradation of these alloys in nuclear power plant environments. Bautista's NCN URE research contributed to two peer-reviewed publications. ${ }^{15-16}$ Following his research experience at Purdue, Bautista transferred to California State University, Northridge, where he has recently graduated with a degree in biochemistry. He will pursue his Ph.D. in chemistry at the University of California, Irvine beginning in the fall 2020.

Following on the success of the pilot program, research opportunities for two-

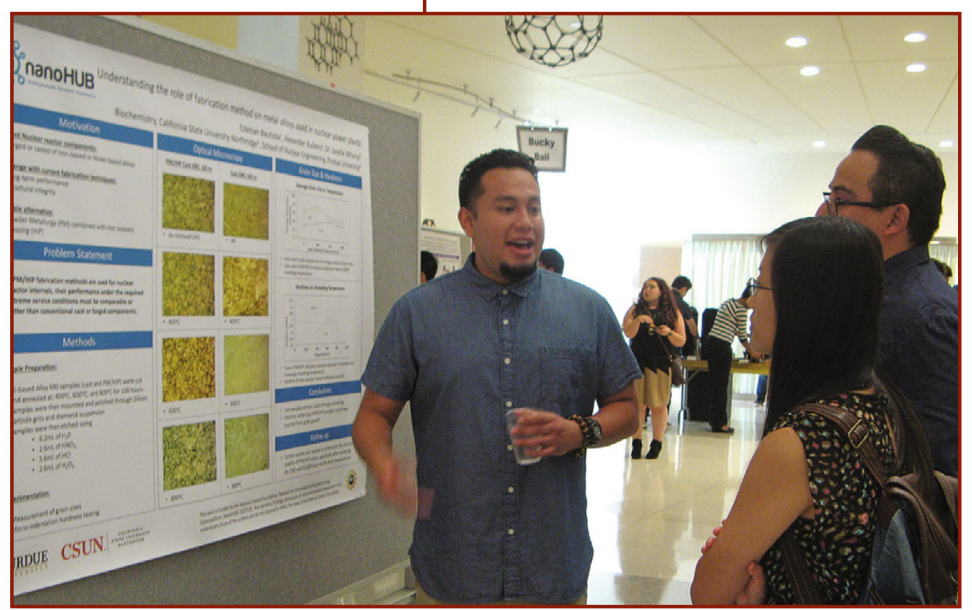

a

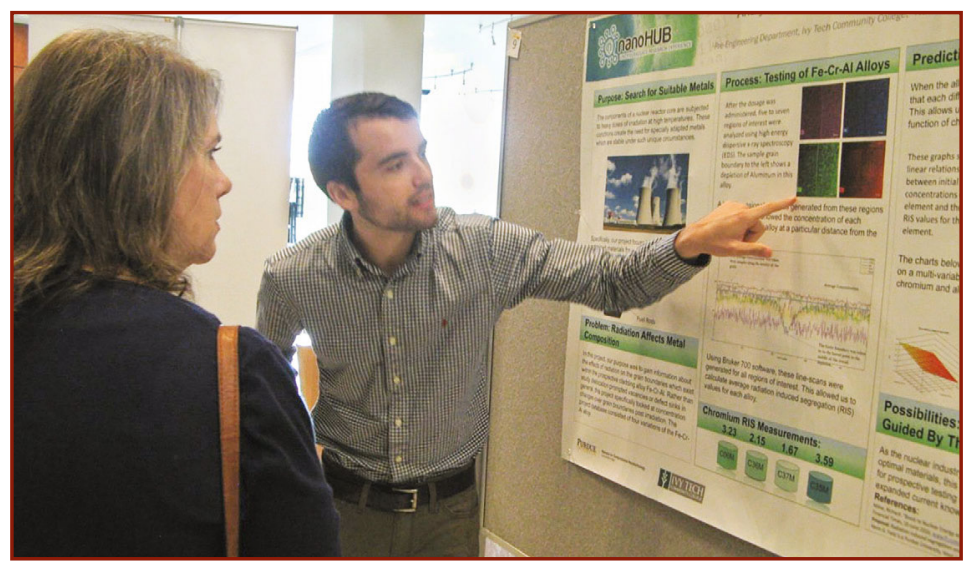

b

Esteban Bautista (photo a) and Timothy Pownell (photo b) present their research posters at the Network for Computational Nanotechnology (NCN) Undergraduate Research Experience (URE) symposium at Purdue University. year and community college students were formally integrated into the NCN URE program. Students were primarily recruited from Ivy Tech Community College of Indiana. Of the Ivy Tech students who transfer to four-year institutions, nearly $15 \%$ matriculate to Purdue, making the NCN URE partnership between Purdue and Ivy Tech a natural fit. Between three and five community college students participate in NCN URE each year. Students from Mt. San Antonio College and Skyline College in California and from Roxbury City College in Massachusetts have also participated in the program. To date, more than 15 students from two-year institutions have participated in the program.

Timothy Pownell is one such student who participated in NCN URE at Purdue in 2018 while he was enrolled at Ivy Tech. Pownell is a first-generation college student. His NCN URE project focused on the phenomenon of radiation-induced grain boundary segregation (RIS) in $\mathrm{FeCrAl}$ alloys, which are candidate alloys for accident-tolerant nuclear fuel claddings. Pownell analyzed composition maps previously acquired by transmission electron microscopy (TEM) with energy dispersive x-ray spectroscopy (EDX). Pownell built a nanoHUB tool that predicts RIS behavior from key parameters he identified, including grain size, irradiated microstructure, and irradiation conditions. This tool lays the foundation for a future machine learning program to predict $\mathrm{RIS}$ in $\mathrm{FeCr}$ alloys. Pownell returned to Purdue in 2019 for summer research and continues materials science research today. He has since transferred to Purdue, where he is pursuing a degree in mechanical engineering, and was selected for a summer internship at a brass foundry.

\section{Lessons Learned}

The program is formally evaluated using the Undergraduate Research Student SelfAssessment, administered anonymously through the Student Assessment of their Learning Gains website. Video interviews have also been conducted with pilot program participants approximately six months following the conclusion of their NCN URE.

Evaluations indicate that the $\mathrm{NCN}$ URE has enhanced self-efficacy in all 
participating two-year college students. This is evidenced by a strengthened determination to attain higher education, an increased desire to transfer to a large research university, and an interest in continued pursuit of research. Students also consistently discuss a heightened confidence in their capabilities overall, their ability to be successful in unfamiliar or new situations, and their ability to achieve goals previously thought unattainable.

A challenge the community college students often cited, however, was difficulty in reconciling the scale of research conducted at a research-intensive institution. Prior to NCN URE, the students' exposure to research at the two-year college level involved seeing the scientific method through, from hypothesis to conclusion. But when they participated in NCN URE, their project was a small task within a larger research scope. This led to "cog in the wheel" feelings and some lack of ownership over their work. However, discussions with their faculty and graduate student mentors about the context of their NCN URE projects helped students understand the scale of federally funded research and improve their sense of accomplishment.

With proper research mentorship and project design, the Purdue NCN URE program enables community college students to improve their self-efficacy and gain research experience that influences their educational and career paths.

\section{Acknowledgements}

The NCN URE program was primarily supported by the Network for Computational Nanotechnology through National Science Foundation (NSF) award EEC-1227020. The student researchers highlighted in this article were also partially supported by NSF award DMR-1752636 and the US Department of Energy Office of Nuclear Energy contract DE-NE0008759.

\section{End Notes}

1. Current Term Enrollment Estimates: Fall 2019, National Student Clearinghourse, 2019. https:// nscresearchcenter.org/wp-content/uploads /CTEE_Report_Fall_2019.pdf.

2. B.K. Townsend and K. Wilson, "A Hand Hold for A Little Bit: Factors Facilitating the Success of Community College Transfer Students to a Large Research University," J. Coll. Stud. Dev., 47 (2006) 439-456.
3. P. Schuetz, "A Theory-Driven Model of Community College Student Engagement," Community Coll. J. Res. Pract., 32 (2008) 305324. doi:10.1080/10668920701884349.

4. V.B. Saenz, D. Hatch, B.E. Bukoski, S. Kim, K. Lee, and P.Valdez, "Community College Student Engagement Patterns: A Typology Revealed Through Exploratory Cluster Analysis," Community Coll. Rev., 39 (2011) 235-267. doi:10.1177/0091552111416643.

5. V. Tinto and P. Russo, "Coordinated Studies Programs: Their Effect on Student Involvement at a Community College," Community Coll. Rev., 22 (1994) 16-25.

6. T.H. Bers and K.E. Smith, "Persistence of Community College Students: The Influence of Student Intent and Academic and Social Integration," Res. High. Educ., 32 (1991) 539-556.

7. S. Goldrick-Rab, "Challenges and Opportunities for Improving Community College Student Success," Rev. Educ. Res., 80 (2010) 437-469. doi:10.3102/0034654310370163.

8. A.L. Zydney, J.S. Bennett, A. Shahid, and K.W. Bauer, "Impact of Undergraduate Research Experiences in Engineering," J. Eng. Educ., 91 (2002) 151-157.

9. S. Kight, J.J. Gaynor, and S.D. Adams, "Undergraduate Research Communities: A Powerful Approach to Research Training," J. Coll. Sci. Teach., 35 (2006) 34-39.

10. D.A. Sabatini, "Teaching and Research Synergism: The Undergraduate Research Experience," J. Prof. Issues Eng. Educ. Pract., 123 (1997) 98-102.

11. D. Lopatto, "Undergraduate Research as a HighImpact Student Experience," Peer Rev. Assoc. Am. Coll. Univ., 12 (2010) 27-30.

12. D. Lopatto, "Undergraduate Research Experiences Support Science Career Decisions and Active Learning," Life Sci. Educ., 6 (2007) 297-306. doi:10.1187/cbe.07.

13. A.Q. Gates, P.J. Teller, A. Bernat, N. Delgado, and C.K. Della-Piana, "Meeting the Challenge of Expanding Participation in the Undergraduate Research Experience," Am. Soc. Eng. Educ. Front. Educ. Conf., Tempe, AZ, 1998. doi:10.1109/FIE.1998.738588.

14. S.H. Russell, M.P. Hancock, and J. McCullough, "Benefits of Undergraduate Research Experiences," Science, 316 (2007) 548-549. doi:10.1126/science.1140384.

15. A.L. Bullens, E. Bautista, E.H. Jaye, N.L. Vas, N.B. Cain, K. Mao, D.W. Gandy, and J.P.Wharry, "Comparative Thermal Aging Effects on PM-HIP and Forged Inconel 690," JOM, 70 (2018) 22182223. doi:10.1007/s11837-018-2818-z.

16. E.M. Getto, B. Tobie, E. Bautista, A.L. Bullens, Z.T. Kroll, M.J. Pavel, K.S. Mao, D.W. Gandy, and J.P.Wharry, "Thermal Aging and Hall-Petch Relationship of PM-HIP and Wrought Alloy 625," JOM, 71 (2019) 2837-2845.
Janelle P. Wharry is an associate professor at Purdue University. A TMS member since 2009, she currently serves on the TMS Nanomechanical Materials Committee, Nuclear Materials Committee, and is the Structural Materials Division representative to the Education Committee.

Timothy Pownell is an undergraduate student at Purdue University. He was a participant in the Network for Computational Nanotechnology (NCN) Undergraduate Research Experience (URE) program at Purdue.

Esteban Bautista recently received his bachelor's degree from California State University, Northridge, and is pursuing his Ph.D. at the University of California, Irvine in fall 2020. He was a participant in the NCN URE program at Purdue.

Tanya Faltens is the educational content creation manager at the Network for Computational Nanotechnology at Purdue University. She has been a TMS member since 2017. 